\title{
Endoscopic Septoplasty: Prospective Study in 50 Cases of DNS
}

\author{
Kanu Singla, Baldev Singh, Sanjeev Bhagat, BS Verma
}

\begin{abstract}
Recently endoscopic septoplasty has emerged as an effective alternative to traditional 'headlight' approaches to septoplasty. Endoscopic septoplasty as a minimal invasive technique can limit the dissection and minimize trauma to nasal septal flap under excellent visualization. The present prospective study was conducted at the Department of ENT at Government Medical College, Rajindra Hospital, Patiala. Fifty cases of either sex in age group of 18 to 50 years suffering from deviated nasal septum were included in the study from May 2010 to November 2012. Among the prevalence of type of nasal septal deviation (Mladina classification), the most common type of nasal septal deviation was type $5(46 \%)$ followed by type $6(16 \%)$, type 2 (10\%), type $4(10 \%)$, type $3(8 \%)$, type $7(8 \%)$ and type $1(2 \%)$. Among chief complaints most common was nasal obstruction in $38(76 \%)$ followed by nasal discharge in $10(20 \%)$, headache in $10(20 \%)$, bleeding in $6(12 \%)$ and postnasal discharge in $4(8 \%)$ patients. There was improvement in nasal obstruction in $78 \%$, nasal discharge in $60 \%$ and postnasal drip in $75 \%$ patients. On objective assessment at last follow-up (3 months), persistent inferior turbinate hypertrophy in $14 \%$, and persistent deviation was seen in $4 \%$ of cases. Synechiae formation was seen in $4 \%$ of cases.
\end{abstract}

Keywords: Endoscopic septoplasty, Deviated nasal septum, Nasal obstruction.

How to cite this article: Singla K, Singh B, Bhagat S, Verma BS. Endoscopic Septoplasty: Prospective Study in 50 Cases of DNS. Clin Rhinol An Int J 2013;6(2):92-95.

Source of support: Nil

Conflict of interest: None declared

\section{INTRODUCTION}

The nasal septum is an important physiological and supportive structure of nose. ${ }^{1}$ Deviated nasal septum has been implicated in various rhinological complaints, which includes nasal obstruction, epistaxis, sinusitis and obstructive sleep apnea. ${ }^{2}$

The uses of nasal endoscopes in rhinological practice have revolutionized the refinements in the diagnosis and treatment of nasal obstruction. The nasal endoscope allows precise preoperative identification of the septal pathology and associated lateral wall abnormalities and helps in better planning of endoscope-aided septal surgery. ${ }^{3}$

In 1991, Lanza et $\mathrm{al}^{4}$ and Stammberger ${ }^{5}$ described the application of endoscopy for the correction of septal deformity. Endoscopic septoplasty has emerged as an attractive alternative to traditional 'headlight' approaches to septoplasty. Endoscopic septoplasty is a minimal invasive technique that can limit the dissection and minimize trauma to nasal septal flap under excellent visualization. This is especially valuable for patients having had previous septal surgery. 6,7

The present prospective study was conducted among 50 patients of deviated nasal septum. This is the largest series in the literature, where endoscopic septoplasty has been performed alone as the primary procedure. Surgical indications, techniques and complications are discussed.

\section{MATERIALS AND METHODS}

The present study is of prospective type, conducted at the Department of ENT at Government Medical College, Rajindra Hospital, Patiala. Fifty cases of either sex in age group of 18 to 50 years suffering from deviated nasal septum with inferior turbinate hypertrophy were included in the study from May 2010 to November 2012.

\section{Inclusion Criteria}

Patients with history of nasal obstruction, nasal discharge, hyposmia, postnasal drip, facial pain and headache with septal spur or deviated nasal septum.

\section{Exclusion Criteria}

Patients with caudal dislocation of septum, gross deviation of the nasal septum, allergic rhinitis, and nasal mass and nasal polyps were excluded from the study.

All patients were subjected to a detailed clinical history about the symptoms and complete ENT examination. Patients were then subjected to routine radiological investigations (X-ray PNS/CT scan nose and PNS) to rule out nasal pathology. A diagnostic nasal endoscopy was performed in OPD under local anesthesia, before taking up the patient for surgery.

Deviated nasal septum was classified according to Mladina ${ }^{9,10}$ who suggested classification of deviated nasal septum into vertical and horizontal types:

Type 1: Midline septum or mild deviations in vertical or horizontal plane, which do not extend throughout the vertical length of the septum.

Type 2: Anterior vertical deviation.

Type 3: Posterior vertical deviation (OM and middle turbinate area).

Type 4: 'S' septum-posterior to one side and anterior to other side. 
Type 5: Horizontal spur on one side with or without high deviation to the opposite side.

Type 6: Type 5 with deep grove on the concave side.

Type 7: Combination of more than one type in types 2 to 6 .

\section{TECHNIQUE}

The patient is positioned, prepared and draped for septoplasty. Topical oxymetazoline is applied for decongestion; $1 \%$ lidocaine with 1:100,000 epinephrine is injected subperichondrially along the septum. The incision for septoplasty is best made contralateral to the side of maximal deviation. For a broadly deviated septum, a standard Killian or hemitransfixion incision is used. For more posterior isolated deformities, the incision may be placed more posteriorly in the immediate vicinity of the deformity, obviating extraneous flap elevation.

Mucoperichondrial and mucoperiosteal flaps are elevated with a Cottle's elevator under direct vision with the help of a $0^{\circ}$ endoscope. The septal cartilage is then incised a few millimeters posterior to the mucosal incision. The deviated portion is removed with the help of an endoscopic scissor or forceps, taking care not to traumatize the opposite flap. The deviated portion of the vomer, or perpendicular plate of the ethmoid, is removed when necessary using gouge and hammer. After complete removal of the spur, the mucoperiosteal flaps are restored to their native position. The nasal cavity was packed with merocel after the procedure. Pack removal was done after 48 to 72 hours of surgery. Patients were followed up after 4 weeks, 12 weeks after the operation.

\section{RESULTS}

In the present study, the male patients to female patient's ratio for deviated nasal septum were 7:3.

Among chief complaints most common was nasal obstruction in $38(76 \%)$ followed by nasal discharge in $10(20 \%)$, headache in $10(20 \%)$, bleeding in $6(12 \%)$ and postnasal discharge in $4(8 \%)$ patients (Graph 1).

Among the prevalence of type of nasal septal deviation (Mladina classification), the most common type of nasal septal deviation was type $5(46 \%)$ followed by type $6(16 \%)$, type $2(10 \%)$, type $4(10 \%)$, type $3(8 \%)$, type $7(8 \%)$ and type $1(2 \%)$ (Graph 2).

There was improvement in nasal obstruction in $78 \%$, headache in $100 \%$, nasal discharge in $60 \%$, bleeding in $50 \%$ and postnasal drip in $75 \%$ of patients (Graph 3).

Septal hematoma was found in $1(2 \%)$, synechiae in 2 $(4 \%)$ and bleeding in $1(2 \%)$ patient (Graph 4$)$.

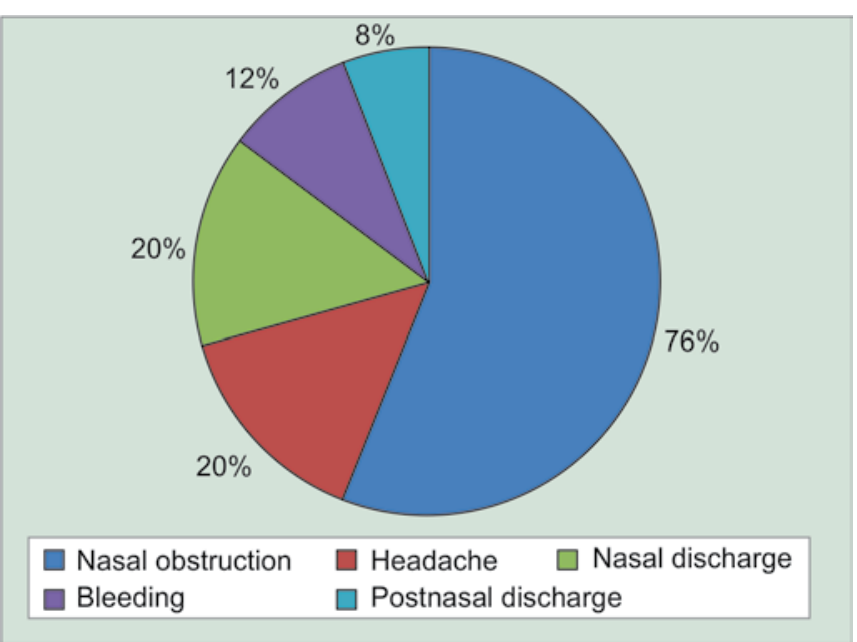

Graph 1: Prevalence of complaints in patients with deviated nasal septum

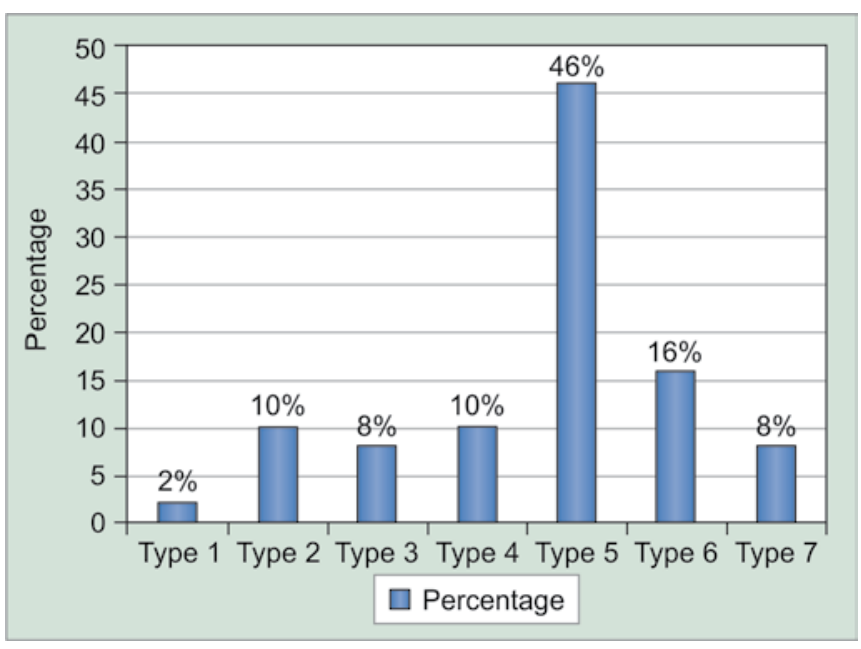

Graph 2: Prevalence of type of nasal septal deviation (Mladina classification)

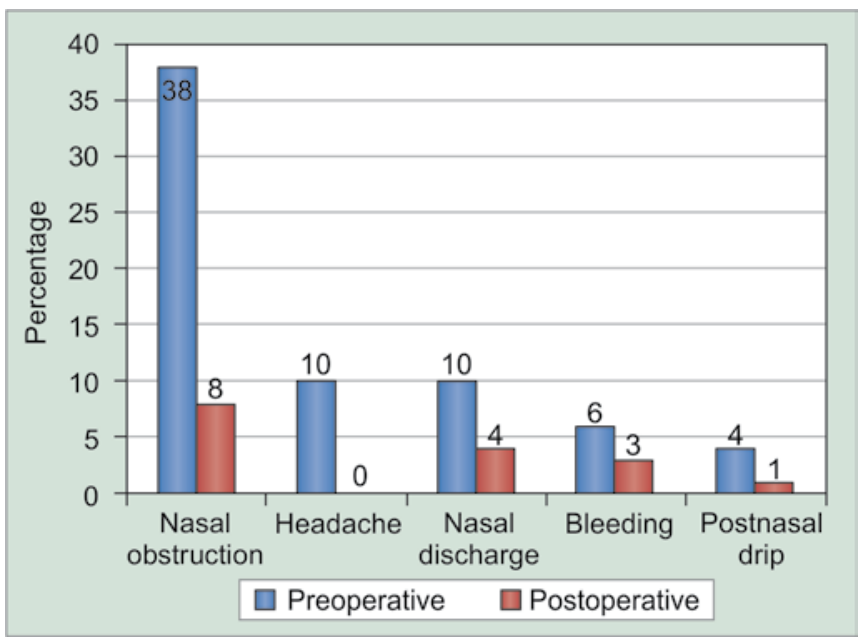

Graph 3: Postoperative percentage improvement in symptoms

\section{DISCUSSION}

Septoplasty is the frequently performed surgical procedure, for deviated nasal septum, often in conjunction with other 


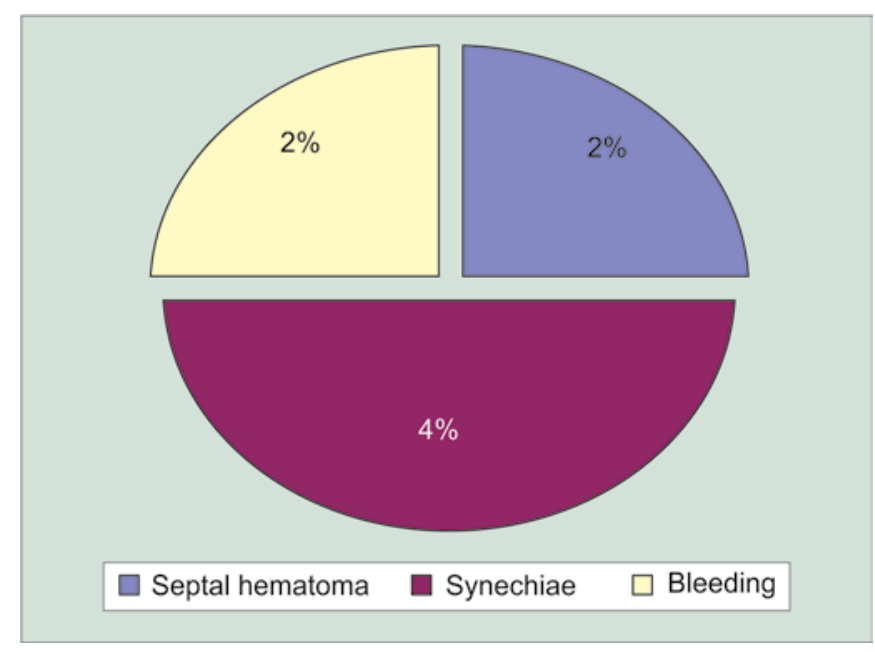

Graph 4: Percentage of immediate postoperative complications

nasal sinus procedure, such as cosmetic rhinoplasty and functional endoscopic sinus surgery. ${ }^{8}$ The endoscopic approach to septoplasty provides several advantages over the standard headlight technique, which include adequate visualization under direct light, less surgical time, helpful in diagnosis and treatment of posterior septal deformities, and improved evaluation of septal deformities in the nasal valve region. Finally, endoscopic septoplasty can be a valuable teaching tool. The use of video monitors to demonstrate surgical anatomy and technique offers significantly greater learning opportunities for surgical assistants, students and operating room staff than does the headlight approach.

In the present study, the male patients to female patient's ratio for deviated nasal septum were 7:3, which was in concordance with the study by Rao et $\mathrm{al}^{11}$ and Jain et al. ${ }^{12}$

In our study, common complaints of patients with septal deflection were found to be nasal obstruction (76\%), nasal discharge (20\%), headache (20\%), and postnasal drip (8\%); these results were similar to the study conducted by Gupta and Motawani ${ }^{13}$ and Jain et $\mathrm{al}^{12}$ in terms of nasal obstruction (75\%), but nasal discharge (55\% and $41 \%$ ) were second major complaint in their study.

Classification of septal deformities have been given by many scientists like Jang et al, ${ }^{14}$ and Guyuron et al ${ }^{15}$ who divided the septal deformities into 5 types while, Mladina et $\mathrm{al}^{9,10}$ described 7 types of septal deformities which was taken as the standard classification in our study to divide the cases for surgery. In the present study commonest type of septal deformity was type 5, i.e. horizontal spur on one side with or without posterior deviation on other side (46\%) and least common was type 1 deformity (2\%), these results are similar with study by Mladina ${ }^{9,10}$ and Rao et al. ${ }^{11}$

In a study by Sindhwani and Wright, ${ }^{16} 54 \%$ patients with complaints of nasal obstruction and facial pain were cured and $38 \%$ showed improvement and $8 \%$ were not benefited.
In the present study there was $78 \%$ improvement in nasal obstruction, $100 \%$ relief from headache, $75 \%$ improvement in postnasal drip. These results are in comparison with study by Jain et al ${ }^{12}$ in which there was $96 \%$ improvement in nasal obstruction, 54\% relief from headache and $40 \%$ improvement in postnasal drip with endoscopic septoplasty.

Follow-up on 3 months postoperative day showed persistent anterior deflection in $6 \%$ and persistent posterior deflection in $4 \%$ patients; these results are comparable with study by Jain et al ${ }^{12}$ in which $3 \%$ patients had persistent posterior deviation, $10 \%$ had persistent anterior deviation.

Complication rate in study by Gupta ${ }^{13}$ was found to be $2.08 \%$ for endoscopic septoplasty. In a study by Hwang et $a l,{ }^{6}$ the complication rate was found to be $5 \%$ for endoscopic septoplasty. In the present study complication rate in endoscopic septoplasty group were septal hematoma $1(2 \%)$, synechiae $2(4 \%)$ and bleeding $1(2 \%)$.

\section{CONCLUSION}

The endoscopic septoplasty facilitates accurate identification of pathology due to better illumination, improved accessibility to remote areas and magnification. It facilitates realignment by limited and precise resection of pathological areas, by precise repair and strategically placed wedge resections. Also, endoscopic septoplasty provides an excellent teaching tool when used in conjunction with video monitors and recording.

\section{REFERENCES}

1. Ridenour BD. The nasal septum. In: Flint PW, Haughey BH, Robbins KT, Thomas JR, editors. Cummings otolaryngologyhead and neck surgery. Missouri: Mosby-Year Book Press; 1998. 921-948 p.

2. Pannu KK, Chadha S, Kaur IP. Evaluation of benefits of nasal septal surgery on nasal symptoms and general health. Indian J Otolaryngol Head Neck Surg 2009;61(1):59-65.

3. Nayak DR, Balakrishnan R, Murthy KD. An endoscopic approach to the deviated nasal septum--a preliminary study. J Laryngol Otol 1998;112(10):934-939.

4. Lanza DC, Kennedy DW, Zinreich SJ. Nasal endoscopy and its surgical application. In: Lee KJ, editor. Essential otolaryngology, head and neck surgery. 5th ed. New York: Elsevier Publishing; 1994. p 373-387.

5. Stammberger H, Hasler G. Functional endoscopic sinus surgery: the Messerklinger technique. Philadelphia: BC Decker; 1991. 432-433 p.

6. Hwang PH, McLaughlin RB, Lanza DC, Kennedy DW. Endoscopic septoplasty: indications, technique and results. Otolaryngol Head Neck Surg 1999 May;120(5):678-682.

7. Chung BJ, Batra PS, Citardi MJ, Lanza DC. Endoscopic septoplasty: revisitation of the technique, indications and outcomes. Am J Rhinol 2007 May-Jun;21(3):307-311.

8. Stewart MG, Smith TL, Weaver EM, Witsell DL, Yuch B, Hannley MT, Johnson JT. Outcomes after nasal septoplasty: results from 
the Nasal Obstruction Septoplasty Effectiveness (NOSE) study. Otolaryngol Head Neck Surg 2004 Mar;130(3):283-290.

9. Mladina R. The role of maxillar morphology in the development of pathological septal deformities. Rhinology 1987 Sep;25(3):199205.

10. Mladina R, Krajina $Z$. The influence of the caudal process on the formation of septal deformities. Rhinology 1989 Jun;27(2):113118.

11. Rao JJ, Kumar EC, Babu KR, Chowdary VS, Singh J, Rangamani SV. Classification of nasal septal deviations-relation to sinonasal pathology. Indian J Otolaryngol Head Neck Surg 2005 July-Sep;57(3):199-201.

12. Jain L, Jain M, Chouhan AN, Harshwardhan R. Conventional septoplasty verses endoscopic septoplasty: a comparative study. People's J Scientific Res 2011 Jul;4(2):25-28.

13. Gupta M, Motwani G. Comparative study of endoscopic aided septoplasty and traditional septoplasty in posterior nasal septal deviations. Indian J Otolaryngol Head Neck Surg 2005 Oct;57(4):309-311.

14. Jang YJ, Wang JH, Lee BJ. Classification of the deviated nose and its treatment. Arch Otolaryngol Head Neck Surg 2008 Mar;134(3):311-315.

15. Guyuron B, Uzzo CD, Scull H. A practical classification of septonasal deviation and an effective guide to septal surgery. Plast Reconstr Surg 1999 Dec;104(7):2202-2209.
16. Sindwani R, Wright ED. Role of endoscopic septoplasty in the treatment of atypical facial pain. J Otolaryngol 2003 Apr;32(2):77-80.

\section{ABOUT THE AUTHORS}

\section{Kanu Singla}

Junior Resident, Department of ENT, Government Medical College and Rajindra Hospital, Patiala, Punjab, India

\section{Baldev Singh}

Professor and Head, Department of ENT, Government Medical College and Rajindra Hospital, Patiala, Punjab, India

\section{Sanjeev Bhagat (Corresponding Author)}

Associate Professor, Department of ENT, Government Medical College and Rajindra Hospital, Patiala, Punjab-147001, India, e-mail: sbent224@gmail.com

\section{BS Verma}

Associate Professor, Department of ENT, Government Medical College and Rajindra Hospital, Patiala, Punjab, India 